\title{
Long-Term Trends in Extreme Precipitation Events over the Conterminous United States and Canada
}

\author{
Kenneth E. KunKel and Karen Andsager \\ Illinois State Water Survey, Champaign, Illinois \\ DAVID R. EASTERLING \\ National Climatic Data Center, Asheville, North Carolina
}

(Manuscript received 5 May 1998, in final form 7 August 1998)

\begin{abstract}
This paper describes the results of an analysis of trends in short duration (1-7 days) extreme precipitation events that have a recurrence interval of $1 \mathrm{yr}$ or longer for stations in the United States and Canada. This definition of extreme precipitation was chosen because such events are highly correlated with hydrologic flooding in some U.S. regions. The dominant temporal characteristic of a national event composite index is significant low-frequency variability. There were lengthy periods of a below-average number of events in the 1930s and 1950 s and an above-average number of events in the early 1940s, early 1980s, and 1990s. Regional variations often differ substantially from the national composite. A simple linear analysis indicates that the overall trend covering the period 1931-96 has been upward at a highly statistically significant rate over the southwest United States and in a broad region from the central Great Plains across the middle Mississippi River and southern Great Lakes basins. The national trend for the United States is upward at a rate of $3 \%$ decade $^{-1}$ for the period 1931-96. While the annual trend for Canada is upward for the period 1951-93, it is not statistically significant. Although the high statistical significance of the results is partially a consequence of the low frequency during the 1930s and 1950s located in the first half of the record, the latter half of the record exhibits an upward trend nearly identical to the entire record. However, an analysis of a 101-yr record of midwestern stations shows that heavy precipitation event frequencies around the turn of the twentieth century (1896-1906) were higher than for other periods of comparable length, except for 1986-96. Although data were not available in digital form to extend the analysis back to 1896 for the entire United States, the midwestern analysis shows that interpretation of the recent upward trends must account for the possibility of significant natural forcing of variability on century timescales.
\end{abstract}

\section{Introduction}

In recent years, heavy precipitation events have resulted in several damaging floods in North America. The most devastating was the 1993 flood in the upper Mississippi River Basin (Kunkel et al. 1994) that resulted in an estimated $\$ 18$ billion in damages (Changnon 1996). Other very serious floods occurred in California and Nevada in January 1997, Quebec in July 1996, and the Red River Basin in April 1997. These events illustrate that society remains vulnerable to climatic extremes. It also raises questions about whether there have been changes in the frequency of flood-producing precipitation events.

Some past studies have examined trends in streamflow and precipitation. Lettenmaier et al. (1994) ex-

Corresponding author address: Kenneth E. Kunkel, Illinois State Water Survey, 2204 Griffith Dr., Champaign, IL 61820-7495.

E-mail:k-kunkel@uiuc.edu amined spatial patterns of mean streamflow and precipitation in the continental United States and found a significant upward trend in both during September-December. Lins and Michaels (1994) also observed increasing trends in streamflow in the fall and winter in many regions of the United States over the period 194188. Changnon and Kunkel (1995) examined trends in hydrologic floods on small and medium-sized streams and in the heavy multiday precipitation events associated with the floods. Their study covered the central United States for the period 1921-85. They found upward trends in both floods and heavy precipitation events over portions of the central United States. Karl et at. (1995a) found that the percent of the United States receiving a much above normal proportion of their annual precipitation from 1-day events in excess of 50.8 $\mathrm{mm}$ increased from about $9 \%$ in the 1910s and 1920s to around $11 \%$ in the 1980 s and early 1990s. More recently, Karl and Knight (1998) found that the 8\% increase in precipitation across the contiguous United 
States since 1910 is reflected primarily in heavy and extreme daily precipitation events, with the definition of heavy and extreme events based on the upper 10 percentiles in the precipitation distribution.

This study examines temporal changes in extreme precipitation events that may be linked to flooding. However, it must be recognized that the link between excessive precipitation and hydrologic flooding is complex and modulated by several factors, including antecedent soil moisture, rate of melt in snowmelt floods, the character of the precipitation events(s) (intensity, duration), and the physical characteristics (size, topography, control structures) of drainage basins. These factors vary from event to event, from season to season, and from region to region. Thus, no single measure of excessive precipitation will correlate highly with hydrologic flooding frequency under all circumstances. This paper describes the results of an analysis of trends in short duration (1-7 days) events that have a recurrence interval of 1 year or longer. This particular measure of extreme precipitation events (multiday, exceeding a return period threshold) was used because a previous study (Changnon and Kunkel 1995) had found a good correlation between such events and hydrologic flood events on small to medium-sized rivers in the Midwest. In that study, they restricted their analysis to flooding on rivers with minimal human control structures in order to more clearly identify the direct link between precipitation and flooding occurrences. Thus, by using this definition, the results presented here will have direct relevance to the frequency of hydrologic flooding in some areas. However, precipitation events of this type may not be highly correlated with certain kinds of floods. For example, snowmelt floods usually depend on frozen precipitation accumulating over a period of several months and the sudden occurrence of high temperatures [e.g., January 1996 flood in Pennsylvania; Leathers et al. (1998)]. As another example, flooding on very large basins often results from excessive precipitation occurring over several weeks or months [e.g., 1993 Mississippi River basin flood; Kunkel et al. (1994)]. In both cases, it is possible that the lengthy period of above-normal precipitation causing snowmelt and large basin floods may include short duration episodes of excessive precipitation that exceed 1 -yr recurrence interval threshold, but it is not essential. Finally, in very arid regions, floods are very infrequent and occur only when precipitation exceeds thresholds for recurrence intervals much longer than considered here.

In addition to flooding frequencies, the results presented here may have relevance to engineering design criteria for structures that handle runoff. Engineering design requirements are based on a recurrence interval threshold for a specific duration, with the exact interval and duration depending on the specific application and the adversity to risk, often dictated by governmental organizations. Studies used for design criteria (Hersh- field 1961; Miller et al. 1993; Huff and Angel 1992) typically include a wide range of event durations (minutes to 10 days) and recurrence interval (subyear to 100 yr).

\section{Data and methods}

The area of study is primarily the conterminous United States although some station records in Canada are also analyzed to provide a broader geographic perspective. This study required data of daily resolution. Several digital datasets were combined to provide the maximum spatial density and length of record, including the following.

- National Climatic Data Center's Summary-of-the-Day (TD-3200) dataset. Although most stations are only available in digital form for the period from 1948 to the present, there are a small number of stations with digitally available data prior to 1948 that were used in this study.

- The U.S. Historical Climatology Network daily dataset (Hughes et al. 1992), which includes about 130 stations with records in many cases extending back to the late $1800 \mathrm{~s}$.

- A set of 246 stations with daily precipitation data extending back to 1896 for nine midwestern U.S. states. $^{1}$

- A set of 63 stations with daily precipitation data for 1951-93 for Canada.

There are well-known errors in precipitation measurements (e.g., Groisman and Easterling 1994). Potentially the most important of these with regard to the measurement of heavy precipitation are losses due to the deformation of the wind field above the gauge orifice. Although this problem is most serious for snow events, there can be errors of $3 \%-10 \%$ for liquid precipitation (Groisman and Legates 1994). Since this study is concerned with trends in heavy precipitation events, of most concern are temporal changes in biases, rather than the magnitude of the biases themselves. The standard method to correct for wind undercatchment is to add a wind shield to the rain gauge. Wind shields were added to a small number of U.S. gauges (less than $3 \%$ of the total number of stations) in the 1940s. However, the vast majority of gauges have remained unshielded throughout the entire period of record and have utilized the same standard $20-\mathrm{cm}$ bucket; thus biases should have negligible effect on the results. In Canada, a new rain

\footnotetext{
${ }^{1}$ This dense network of long-term stations with daily data was the result of a collaborative effort between the Midwestern Climate Center and the State Climatologists in the Midwest to digitize pre-1948 daily data (Kunkel et al. 1998). This includes the states of Illinois, Indiana, Iowa, Kentucky, Michigan, Minnesota, Missouri, Ohio, and Wisconsin. When combined with 1948-present data from TD-3200, long-term records are achieved.
} 
(a)

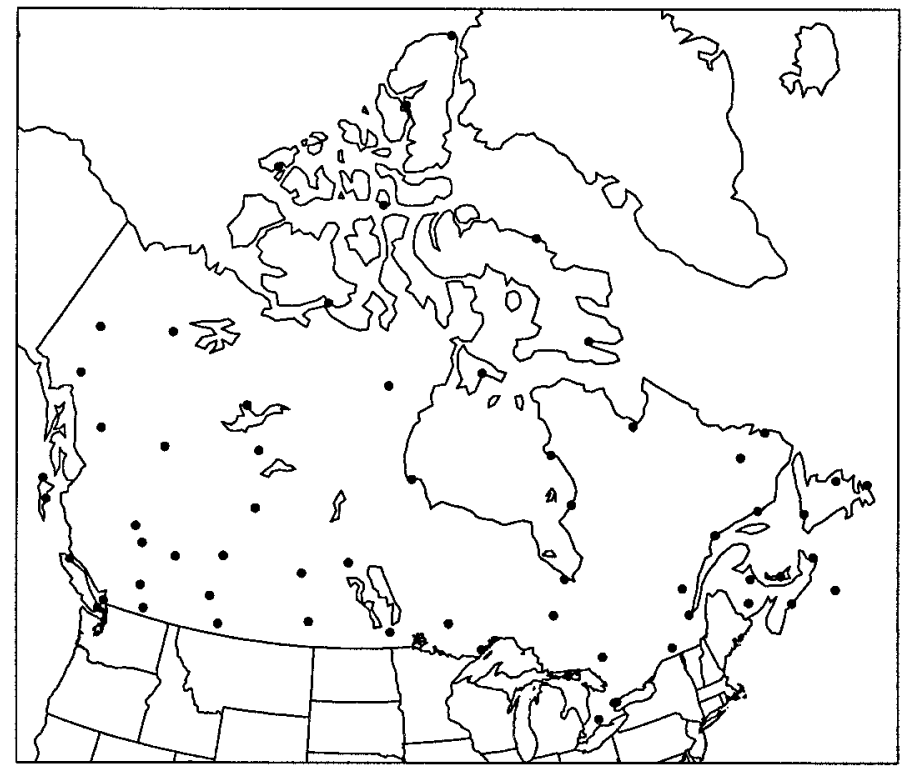

(b)

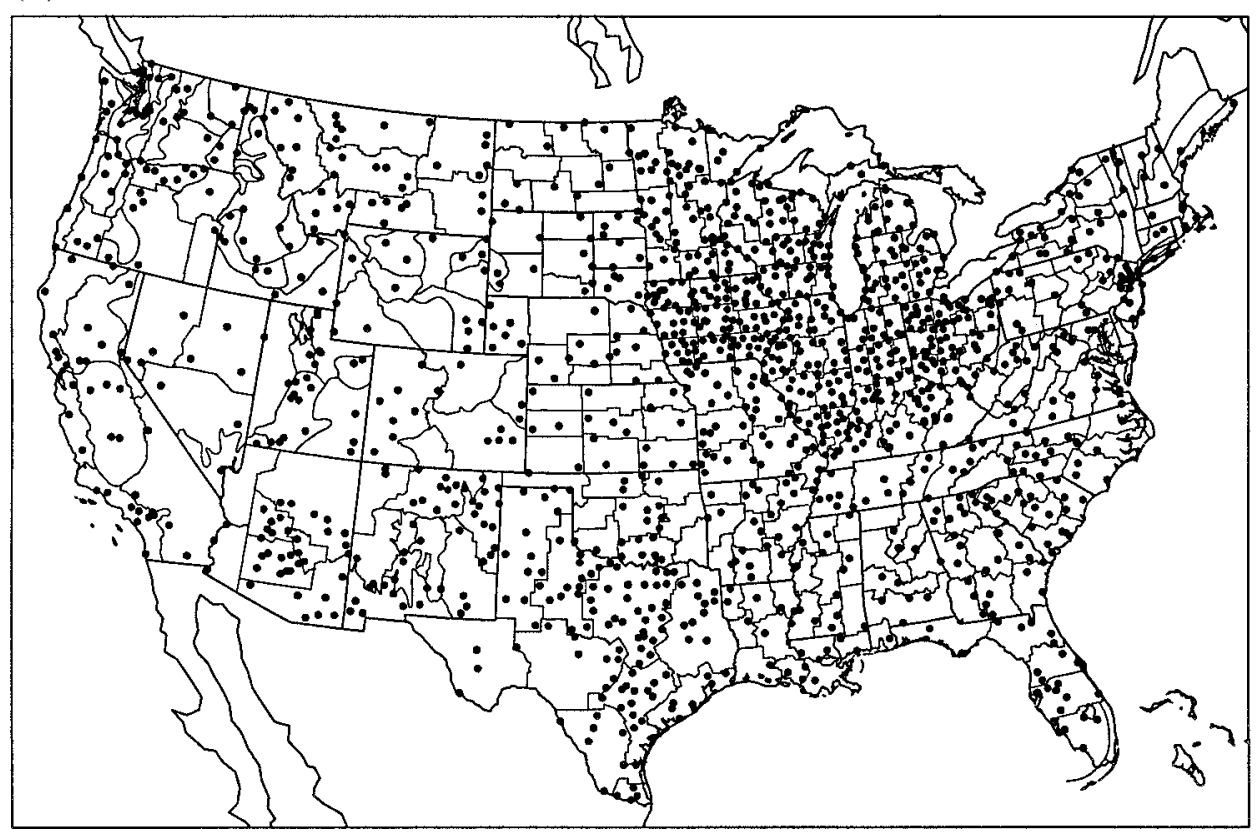

FIG. 1. Distribution of U.S. and Canadian stations used in this study. (a) 63 Canadian stations for the period 1951-93. (b) 1295 U.S. stations for the period 1931-96. Heavy lines show state boundaries, light lines show climate division boundaries.

gauge was introduced over the entire work in the mid1970s. This gauge is estimated to catch $1 \%-4 \%$ more rainfall than the previous gauge (Goodison and Louie 1986). Following Karl et al. (1993), we have corrected the Canadian rain gauge data prior to 1975 by a factor of 1.025 .

Analysis was performed only on stations with nearly complete (less than 5\% missing) data for the period of interest. There is an adequate number of stations meet- ing the missing data criterion to provide good coverage of the entire United States for the period 1931-96, with 1295 stations representing 307 out of 345 climate divisions for the conterminous United States (the area of these 307 climate divisions includes $94.6 \%$ of the area of the conterminous United States, Fig. 1). For periods prior to 1931, the number of climate divisions with no stations increases rapidly. Analysis was also performed for 1896-1996 on the set of 246 stations for the nine 
(a)

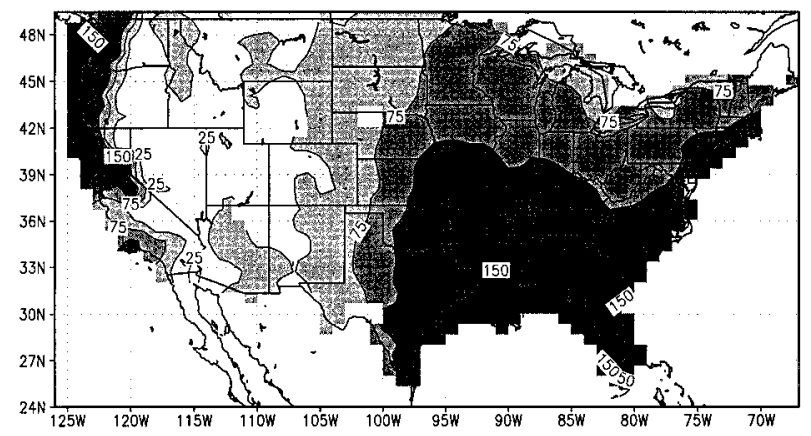

(c)

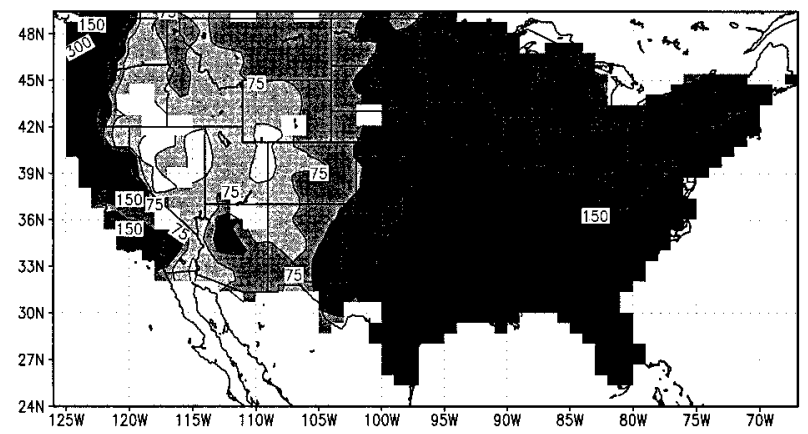

(b)

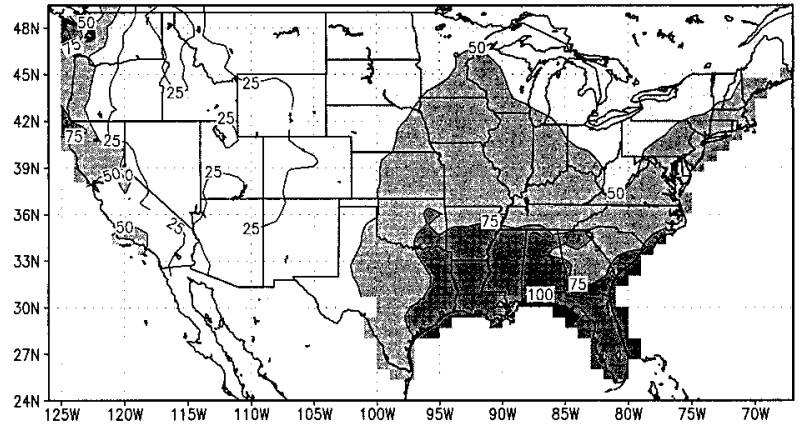

(d)

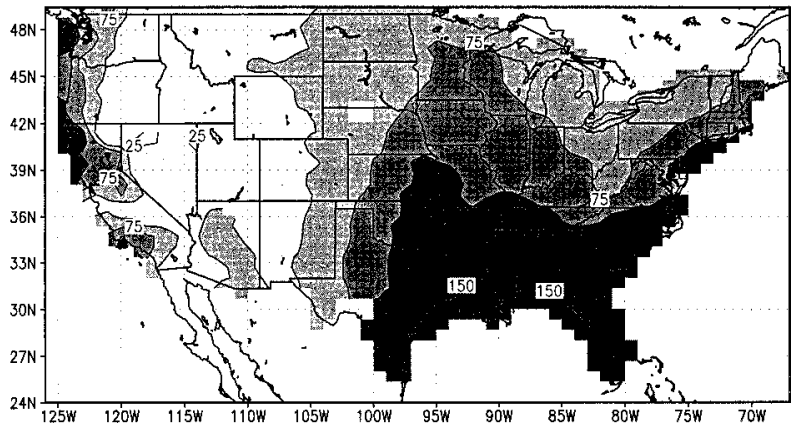

FIG. 2. Threshold (mm) for precipitation events of (a) 7- and (b) 1-day duration exceeding a 1-yr recurrence interval and (c) 7- and (d) 1day duration exceeding a 5-yr recurrence interval for the United States. Shading intervals are 25, 50, 75, 100, 150, 200, and 300 mm.

midwestern states. This analysis provides insight into trends in the early part of the twentieth century. The distribution of Canadian stations used for the analysis of the period 1951-93 is shown in Fig. 1, revealing a much less dense network than for the United States.

Event durations of 1, 3, and 7 days were examined. Two precipitation total thresholds were used to screen events for use in the analysis, defined by recurrence intervals of 1 and $5 \mathrm{yr}$. The thresholds were determined for each station; for example, for 7-day events with a 1 -yr recurrence interval, the largest 66 7-day precipitation totals in the period 1931-96 were identified, the threshold being the smallest of these 66 values. The thresholds for 7-day, 1-yr precipitation events (Fig. 2a) range from less than $25 \mathrm{~mm}$ in the desert regions of the southwest United States to more than $150 \mathrm{~mm}$ along the coasts of the Gulf of Mexico, southern Atlantic Ocean, and northern Pacific Ocean. The thresholds for 1-day, 1-yr precipitation events (Fig. 2b) range similarly from less than $15 \mathrm{~mm}$ to more than $100 \mathrm{~mm}$. The thresholds for 3-day events are about $80 \%$ of those for 7-day events. The thresholds for 7-day, 5-yr (Fig. 2c) events are about $150 \%$ of those for 7 -day, 1-yr events, ranging from around $50 \mathrm{~mm}$ in the desert regions to more than $200 \mathrm{~mm}$ in the coastal regions and up to $400 \mathrm{~mm}$ along the northwest Pacific coast. The thresholds for 1-day, 5 -yr events (Fig. 2d) range from around $25 \mathrm{~mm}$ to greater than $150 \mathrm{~mm}$, with the highest values occurring along the Gulf Coast.
For each station, the annual number of events for each duration and recurrence interval were identified. To assess regional trends for the conterminous United States, station values were arithmetically averaged for climate divisions. The climate division values were then averaged with area weighting to derive regional and national values. To assess national trends for Canada, station values for all 63 Canadian stations were arithmetically averaged.

No assumptions were made concerning the hypothesized causes of any observed trends. Thus the analysis was restricted to testing for simple linear trends. The null hypothesis is that the fluctuations in the frequency of these events are random in time. The Kendall $\tau$ statistic (Hirsch et al. 1982) was used to test for trend. This nonparametric test is particularly useful for analysis of extreme climate events that are not necessarily normally distributed. This test is based on the count of pairs of data values in the time series for which the difference is either positive or negative (looking forward in time), rather than the magnitude of the difference, which helps minimize the effect of extreme values. The test accounts for ties. The Kendall slope estimator algorithm (Hirsch et al. 1982) was used to estimate the magnitude of the trend. This algorithm minimizes the effects of extreme values on the estimated trend by taking the median of all slopes calculated from all possible pairs of data in the time series.

Because of the spatial correlation of extreme precip- 


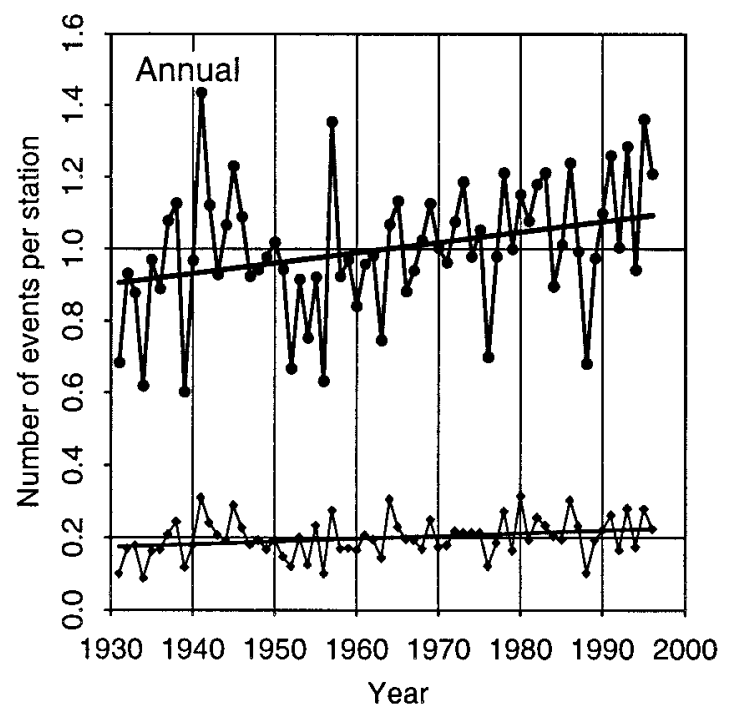

FIG. 3. Nationally averaged annual U.S. time series of the number of precipitation events of 7-day duration exceeding 1-yr (dots) and 5 -yr (diamonds) recurrence intervals.

itation events, one may expect that if one climate division exhibits trends with local significance, then neighboring climate divisions are more likely to also show significance. To determine the field significance for all climate divisions in the United States, we used a Monte Carlo technique suggested by Livezey and Chen (1983). The annual time series for each climate division was randomly shuffled by year, with all climate divisions shuffled the same way for each trial to preserve spatial correlations. For each of 500 random trials, the percent area of the United States with local significance at the 5\% level (two-tailed test) was calculated. The 500 values of percent area with local significance were then used to construct a histogram to which the actual percent area could be compared to determine the probability with which it would occur by chance.

\section{Results}

\section{a. Trends in extreme precipitation events}

The composite time series of 7-day, 1-yr events for the conterminous United States (Fig. 3) is notable for large interannual and decadal-scale variability. Several key climate events noted for severe drought or moisture surpluses are easily evident in this extreme event time series. For example, droughts in the 1930s, early 1950s, 1963,1976 , and 1988 were characterized by a low number of events. In several years in the 1990s, as well as 1941 and 1957, the United States experienced a high number of events. Decadal-scale variability is substantial. Periods of below-average frequency in the 1930s and 1950s were separated by a period in the 1940s of above-average frequency. The 1960s and 1970s were characterized by generally low interannual variability and near to slightly above-average frequency. Increased interannual variability is observed in the 1980s and 1990s with many years experiencing above-average frequency. The variability of the time series of 7-day, 5-yr events is very similar to that of the $1-y r$ recurrence events.

A linear trend analysis using Kendall's slope estimator statistic indicates that the overall trend in 7-day, $1-y r$ events for the conterminous United States is upward at a rate of about $3 \%$ decade $^{-1}$ for $1931-96$. The test using the Kendall $\tau$ statistic indicates that this trend is highly statistically significant (at the $0.5 \%$ level). The trend for 5-yr precipitation events (Fig. 3) is upward at a rate of about $4 \%$ decade $^{-1}$ and is also statistically significant. The statistical significance of the results may be heavily influenced by the fact that the early part of the record included periods of severe drought (the 1930s and early 1950s). To examine the influence of this, the analysis was repeated for a range of beginning years from 1936 to 1976 (i.e., 1936-96, 1941-96, etc.). For all beginning years through 1966, the trend remains upward at a rate of $2.5 \%$ or more per decade and statistically significant at a 5\% level. For beginning years after 1966 , the trend is also upward at $4 \%$ or more per decade but it is not statistically significant. The failure to pass tests of significance, despite the fact that the magnitude of the trend does not decrease, is a result of the shortness of the record and the high-interannual variability of the time series.

The linear trend analysis was applied to the 1931-96 climate division time series for 7-day, 1-yr events (Fig. 4). The largest upward trends (25\% to more than $100 \%$ relative to the 1931-96 mean) have occurred over the southwest United States and in a broad region from the central Great Plains across the middle Mississippi River and southern Great Lakes basin. These trends are statistically significant at the 5\% level, two-tailed test, for climate divisions representing $10.1 \%$ of the area of the United States. By contrast, there are only a few climate divisions with downward trends. These are located in the northwest United States and Florida. The Monte Carlo technique indicates that the probability of finding $10.1 \%$ of the area of the United States with local significance by chance is about $4 \%$, indicating that the field significance of the trends shown in Fig. 4 is statistically significant. A second analysis using the shorter 196696 period resulted in upward trends over a very similar area, primarily the central and southwestern regions of the United States.

Climate division trends for events of shorter duration (1- and 3-day events) are very similar to those of 7-day events with 1-yr recurrence. This is not surprising since there is considerable overlap among the time series for the various durations; that is, within many of the 7-day events, there are 1- and 3-day precipitation totals that exceed the threshold for a 1- or 5-yr recurrence. For 1-day events with 1-yr recurrence, climate divisions representing $9.0 \%$ of the area of the United States show local statistical significance. For events with 5-yr re- 


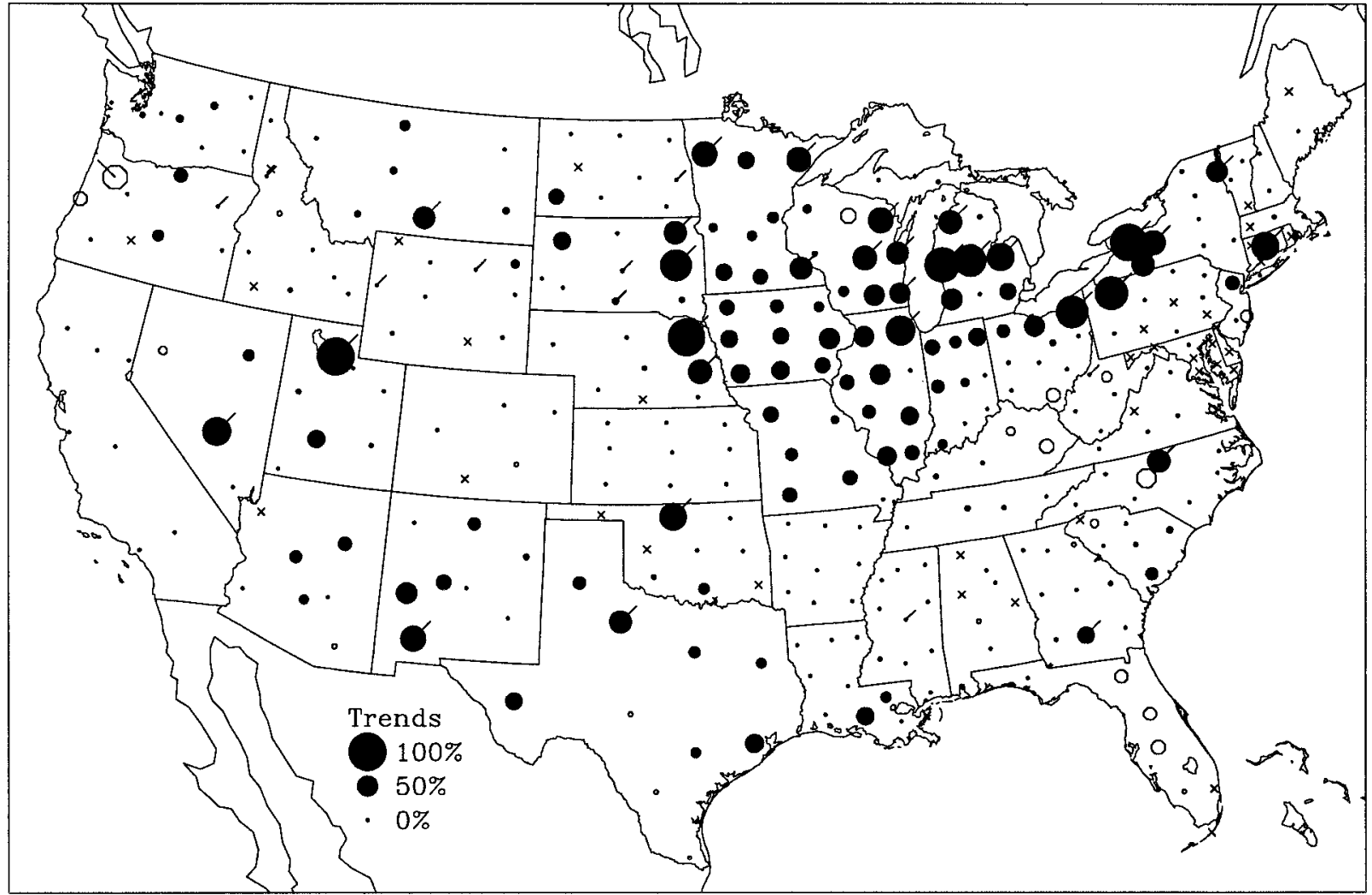

FIG. 4. United States climate division trends in frequency of precipitation events of 7-day duration exceeding a 1-yr recurrence interval for 1931-96. Shaded circles indicate upward trends while open circles indicate downward trends. The magnitude of the trend is given in terms of the percent increase or decrease over the period 1931-96, relative to the 1931-96 mean. As indicated by the key, the magnitude of the trend is linearly proportional to the radius of the circle. A tail attached to the upper right indicates positive trends with local significance at the 5\% level, two-tailed test; a tail attached to the upper left indicates locally significant negative trends. An " $X$ " indicates a climate division with no stations with complete records for the period 1931-96.

currence, the large number of ties in the calculation of the trend leads to a trend estimate, which is based on the median of all slopes, that is numerically zero for almost all of the climate divisions in the United States. Even so, since the Kendall $\tau$ statistic is based on the count of positive and negative slopes, it can still indicate that the presence of a trend is statistically probable if most of the nonzero slopes are of the same sign. For 7-day events with 5-yr recurrence, climate divisions representing only $3.1 \%$ of the area of the United States show local statistical significance; for 1-day events, $6.9 \%$ of the area. These climate divisions are located in the same general region for which significance was found for events with 1-yr recurrence, that is, the southwest and across the central Great Plains through the middle Mississippi River and into the southern Great Lakes basin.

The composite time series for each of the nine climate regions in the United States, shown in Fig. 5, generally show upward trends. Only the northwest and southeast have experienced overall downward trends. The trend for the east north central region is statistically significant at the 5\% level (Table 1). The other trends are not sta- tistically significant. There are sizable differences in low-frequency variability among the regions. Belowaverage frequency in the early 1930s was common to all regions. Above-average frequency in the early 1940s was primarily experienced in the west, south, and north central regions. Below-average frequency in the early 1950s was widespread, but did not occur in the northeast and east north central regions. The very low frequency in the northeast region during the 1960s contrasted with near-average frequency in the rest of the United States. Below-average frequency in the late 1980s occurred primarily in the western regions, while frequency in the northeast was well above average. During the 1990s, most regions have experienced an above-average frequency.

Decomposition of the national composite time series into its seasonal components provides further insight into the nature of the observed trends. In the Midwest and Great Lakes basins, where locally significant upward trends were identified (Fig. 4), the 7-day, 1-yr events occur most frequently in the summer and also occur with some frequency in the spring and fall (Fig. 6). Most events occur in the summer for stations in the 


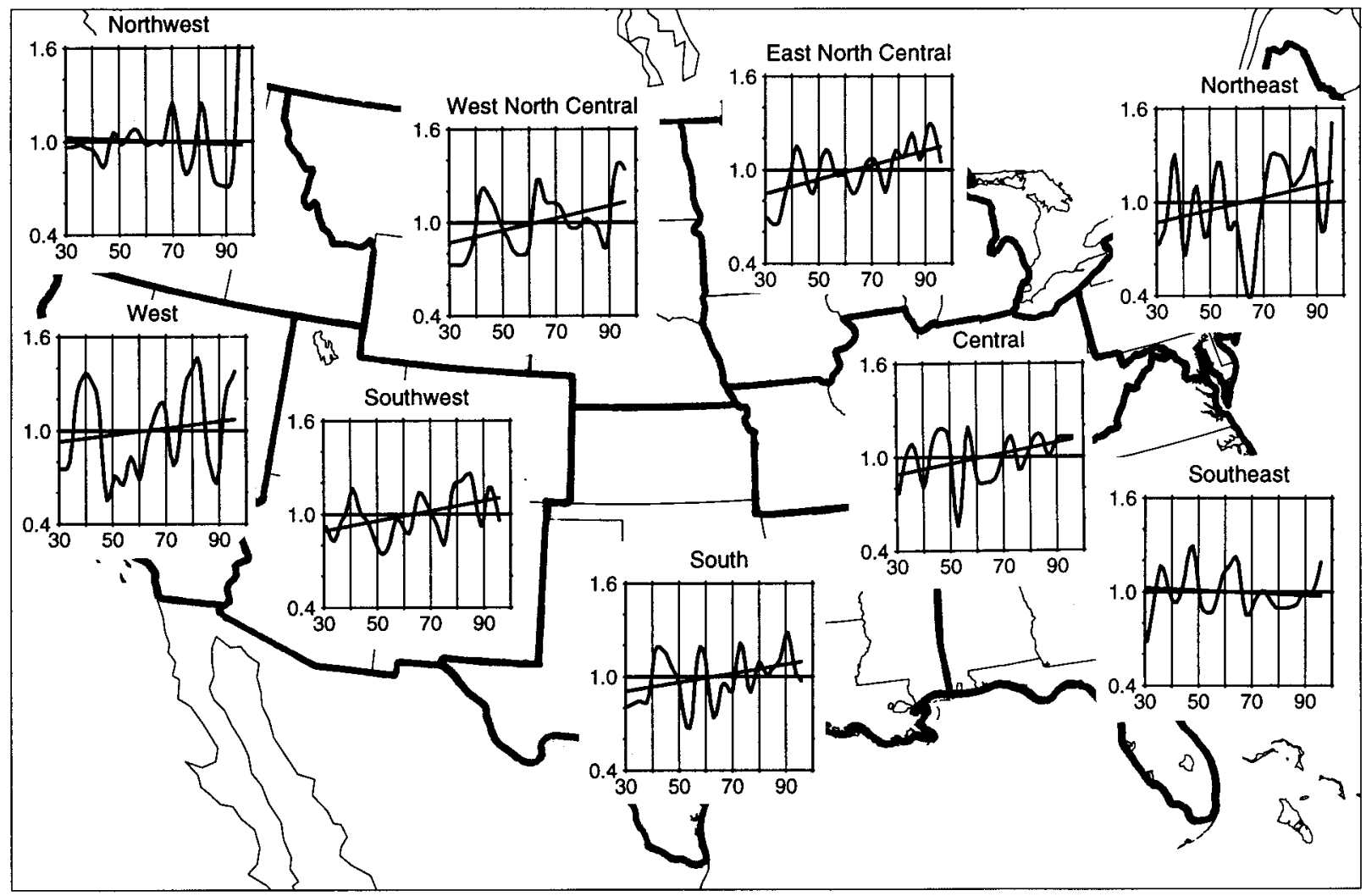

FIG. 5. Trends in frequency of precipitation events of 7-day duration exceeding 1-yr recurrence interval for 1931-96 for the nine climate regions of the United States. For each region, the trend given by the Kendall slope estimator is shown with a smoothed time series of the annual number of precipitation events (each series smoothed with a 3-yr running mean applied twice).

Great Plains. Events occur more equally in the spring, summer, and fall in the northeast and the south. On the west coast, the heavy precipitation events tend to occur in the winter. For those climate divisions where locally significant upward trends were identified in the annual

TABLE 1. Trends for 7-day, 1-yr recurrence precipitation events by region for the United States for the period 1931-96. The trend is given in number of events per station per year and in parentheses the percent change over the entire $66-y r$ period. The $\mathrm{Z}$ scores with magnitude greater than 1.98 are statistically significant at the $5 \%$ level, two-tailed test.

\begin{tabular}{lcrc}
\hline \hline & & & \begin{tabular}{c} 
Percent \\
area of \\
United \\
\multicolumn{1}{c}{ Region }
\end{tabular} \\
Northeast & Trend & Z score & States \\
East north central & $0.0040(+22 \%)$ & 1.63 & 4.8 \\
Central & $0.0046(+26 \%)$ & 3.00 & 8.9 \\
Southeast & $0.0034(+19 \%)$ & 1.87 & 10.8 \\
West north central & $-0.0009(-5 \%)$ & -0.55 & 9.4 \\
South & $0.0040(+22 \%)$ & 1.76 & 15.3 \\
Southwest & $0.0029(+16 \%)$ & 1.38 & 19.2 \\
Northwest & $0.0032(+18 \%)$ & 1.59 & 14.1 \\
West & $-0.0007(-4 \%)$ & -0.24 & 8.1 \\
United States & $0.0021(+10 \%)$ & 0.63 & 9.4 \\
\hline & $0.0029(+16 \%)$ & 3.16 & \\
\hline
\end{tabular}

time series, the greatest seasonal contribution is from the summer, with some also in the spring and fall. Essentially no climate division shows significant trends in the winter. Also, outside of the regions with significant annual trends identified, no other climate division shows large upward and downward seasonal trends that may cancel out when the annual trend is examined.

On a national average, $37 \%$ of the 7 -day, 1 -yr events occur in the summer, $25 \%$ in the fall, $21 \%$ in the spring, and $16 \%$ in the winter. The spring, summer, and fall components of the annual U.S. national composite time series (Fig. 7) each show a moderate upward trend, although they are not statistically significant. The winter component shows no trend. The flood year of 1993 in the upper Mississippi River basin was characterized by a relatively high number of heavy precipitation events in the summer, with an average of 0.64 events per station (Fig. 7c) instead of the long-term average of 0.37 events per station. The average number of events per station was also above average the previous winter (Fig. 7a), with these events occurring primarily in the southwest and California. The average number of events per station for the United States was below average for the spring and fall of 1993 (Figs. 7b and 7d). An examination of 


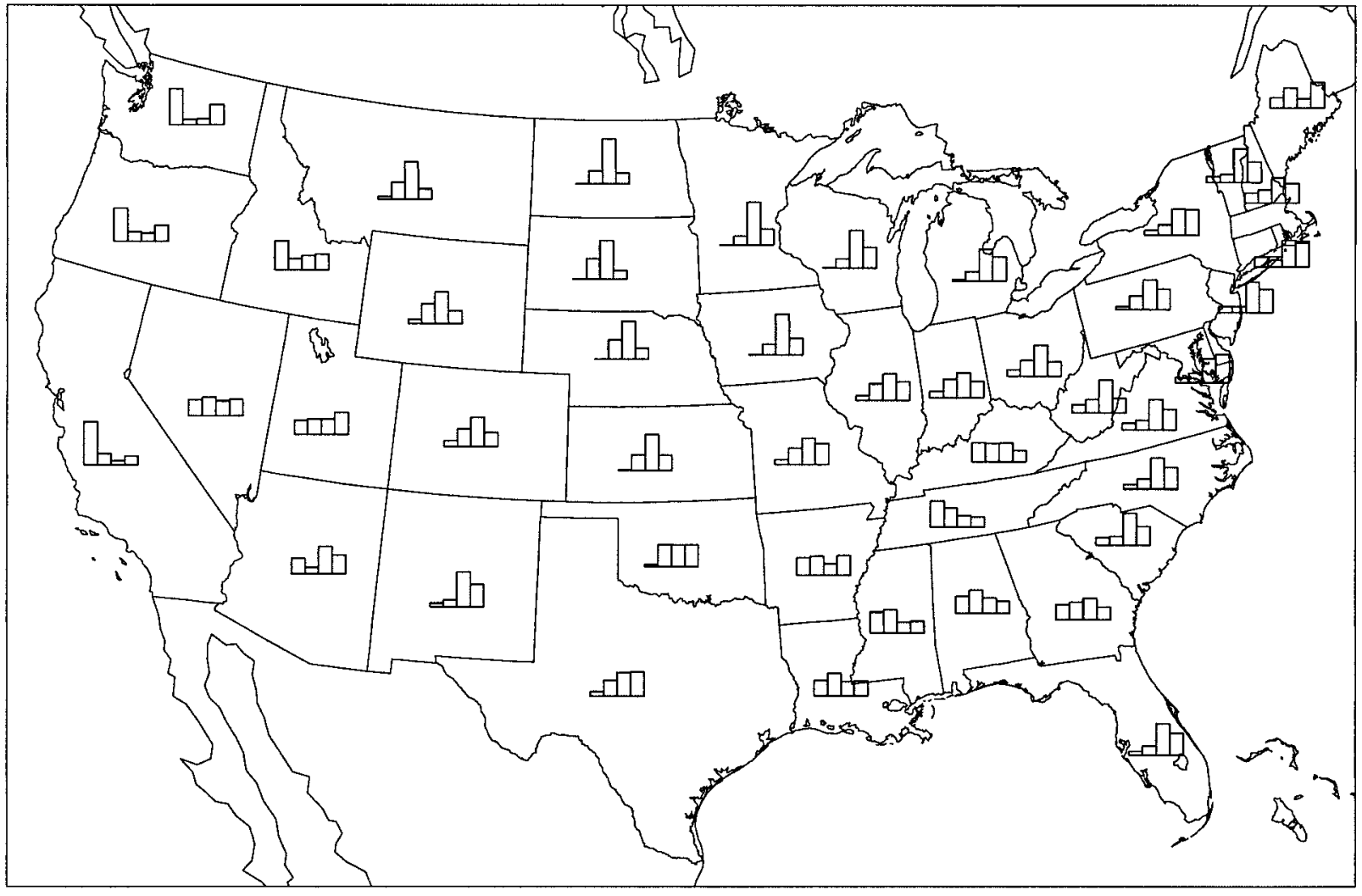

FIG. 6. Relative fraction of 7-day, 1-yr precipitation events occurring in each season for 1931-96 for each state in the Unites States, in the order: winter, spring, summer, fall.

other individual years with a high frequency indicates that the above-average frequency is concentrated in one or two seasons; this is exemplified by the three highest years of 1941 (summer and fall), 1957 (spring), and 1995 (spring).

The annual time series and seasonal components for 7-day, 1-yr, and 7-day, 5-yr precipitation events in Canada are shown in Fig. 8 for the period 1951-93. The trends are generally similar to those for the United States, upward but not statistically significant for the annual series, generally upward but not significant for spring, summer, and fall, and near zero for winter. The variations in the year-to-year Canadian values are not similar to the United States. Canada did not experience a low frequency of events in the early 1950s, 1963, 1976, or 1988, but rather in the mid-1950s, as well as 1987 and 1989. Also, the U.S. high-frequency years of 1957 and 1993 were not above average in Canada. While the number of events was high in the spring of 1993, the number for the entire year was slightly below average. In Canada, the greatest number of events occurred in 1984.

\section{b. Contribution to annual precipitation trends}

The trend in total annual precipitation for U.S. climate divisions (Fig. 9), based only on the long-term stations used in this study, shows upward trends of $20 \%$ or more in the Southwest, Great Plains, and parts of the upper Mississippi River valley and Great Lakes basins. These upward trends are locally significant for over $20 \%$ of the area of the United States. The field significance of this distribution is better than $1 \%$.

The fraction of the total annual precipitation that is contained in the 7-day, 1-yr precipitation events varies from about $10 \%$ along the east coast to about $20 \%$ in the Great Plains and Rocky Mountain regions of the United States, and reaches $30 \%-40 \%$ in the desert regions of the western United States. The average total annual precipitation per station for the United States is shown in Fig. 10, along with the statistically significant trend of about $1.3 \%$ decade $^{-1}$. Removing the precipitation from 7-day, 1-yr events for each station drops the average mean annual total precipitation from 26.7 to 22.6 in. (15\%). The trend also drops, to about $0.9 \%$ decade $^{-1}$, so the trend in the 7-day, 1 -yr events accounts for about $30 \%$ of the trend in average annual precipitation for the United States. For the 70 climate divisions with locally significant upward trends in total annual precipitation, the precipitation included in the 7-day, $1-y r$ events contributes about one-third of the trend on average. 

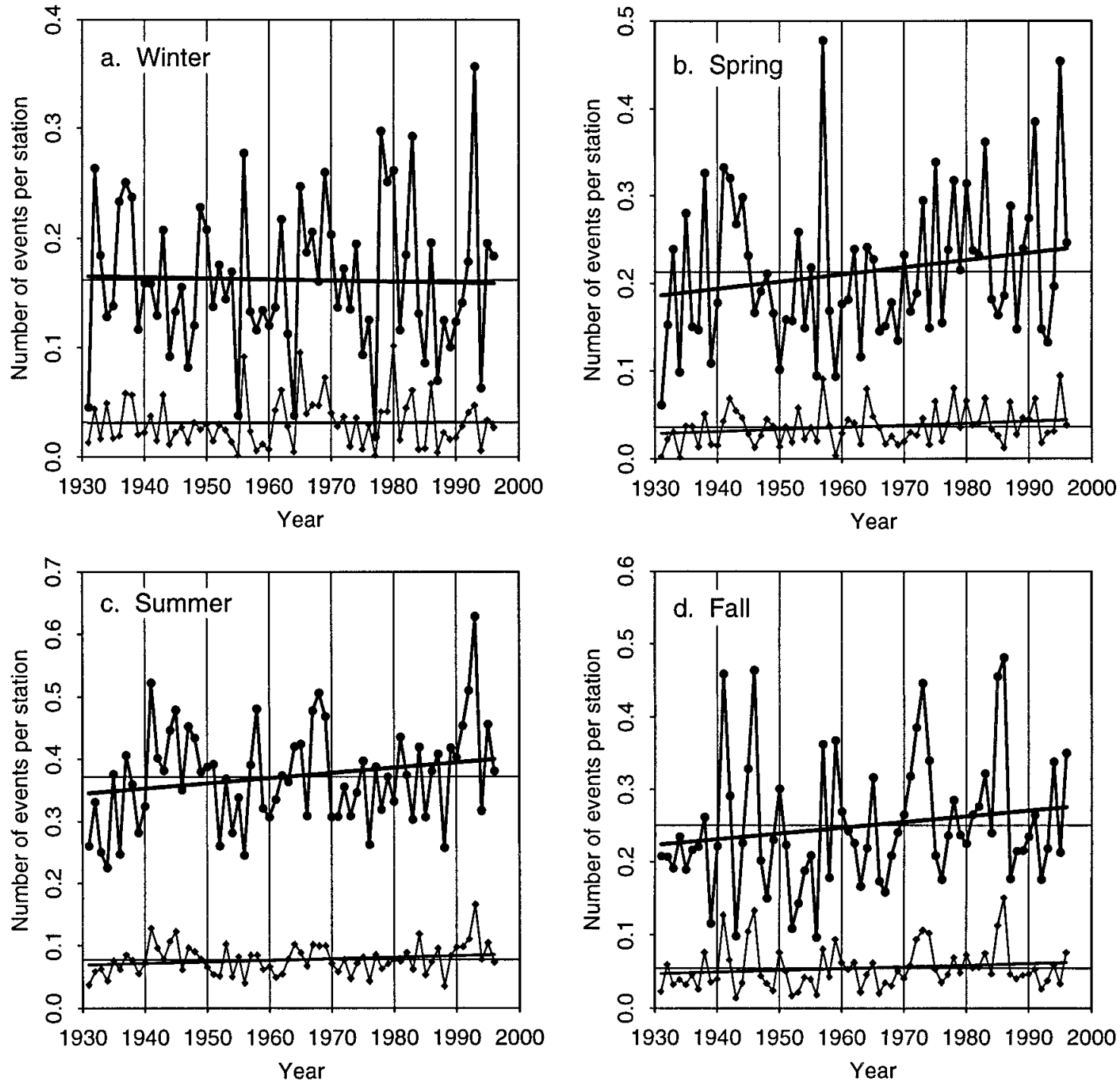

FIG. 7. Nationally averaged U.S. time series of the number of precipitation events of 7-day duration exceeding 1- (dots) and 5-yr (diamonds) recurrence intervals for 1931-96 for (a) winter, (b) spring, (c) summer, and (d) fall. Each seasonal time series is scaled to show its relative contribution to the annual index. The solid bold lines are the trends given by the Kendall slope estimator.

\section{c. Trends in the midwestern United States}

A longer perspective on the changes in 7-day, 1-yr precipitation events is provided in Fig. 11, a 101-yr time series for the Midwest (1896-1996). This time series shows that the Midwest has experienced sizeable multidecadal variability in the frequency of events. Around the turn of the century, the frequency was relatively high. The frequency decreased to a minimum in the 1930s and has generally increased since then. A linear trend analysis applied to the entire time series gives an upward trend; however, because of the high frequency around the turn of the century, the trend is rather small and not statistically significant. The results for 1-day and 3-day duration events (not shown) are similar in all important respects.

\section{Conclusions}

The definition of events with extreme precipitation used in this study is based on recurrence interval (1and 5-yr), which leads to station-specific thresholds, and duration (1, 3, and 7 day). This contrasts with the heavy precipitation trend analyses of Karl et al. (1995a, b), who used a fixed threshold $(50.8 \mathrm{~mm})$ restricted to 1 -day duration. The present analysis weights all regions equally, including the arid regions of the United States, where single-day precipitation amounts greater than $50 \mathrm{~mm}$ are rare. Thus, the trends noted in this study may contain a relatively greater contribution from arid regions and a lesser contribution from wetter regions than described in Karl et al. (1995a, b). In the more recent study of Karl and Knight (1998), they examined trends in the 

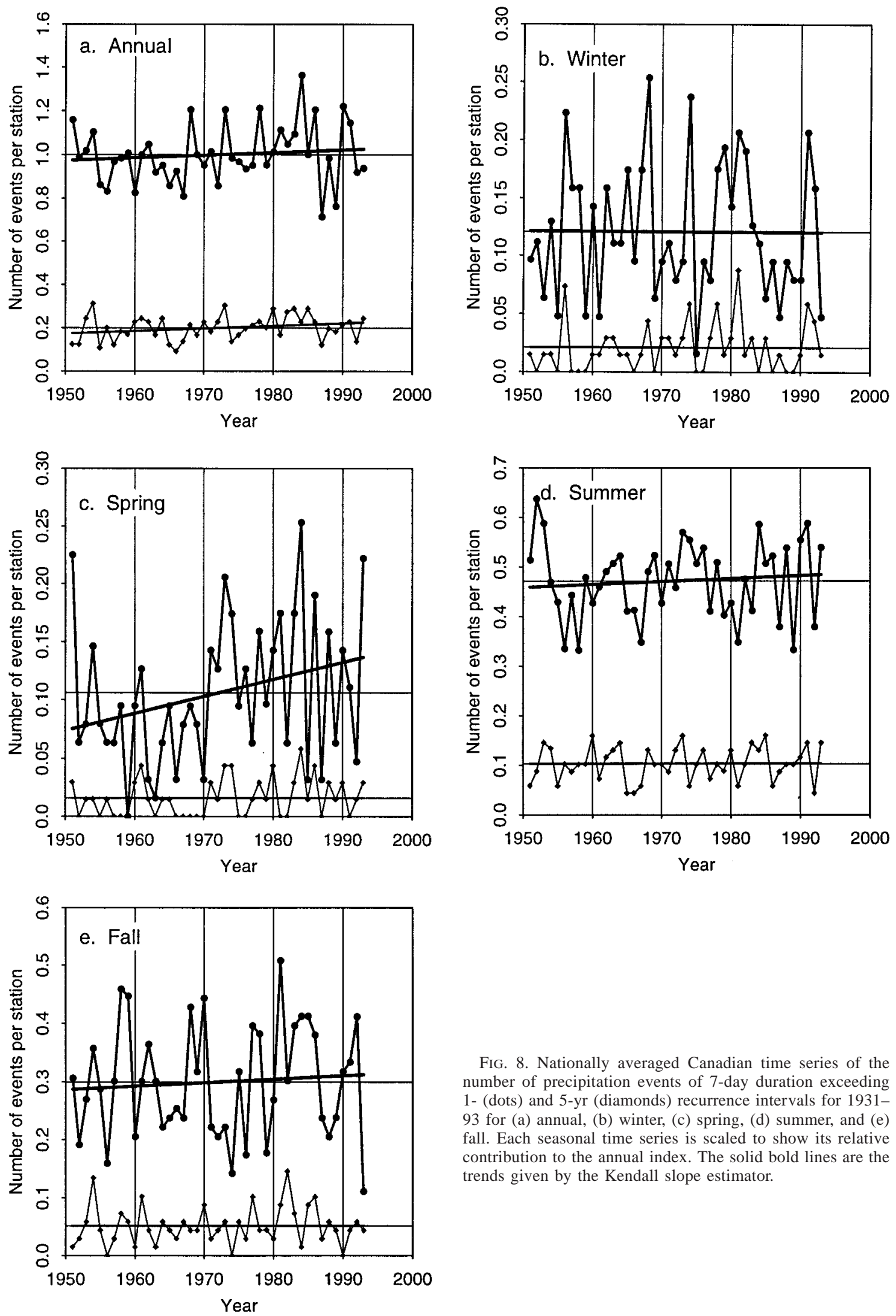

FIG. 8. Nationally averaged Canadian time series of the number of precipitation events of 7-day duration exceeding 1- (dots) and 5-yr (diamonds) recurrence intervals for 193193 for (a) annual, (b) winter, (c) spring, (d) summer, and (e) fall. Each seasonal time series is scaled to show its relative contribution to the annual index. The solid bold lines are the trends given by the Kendall slope estimator. 


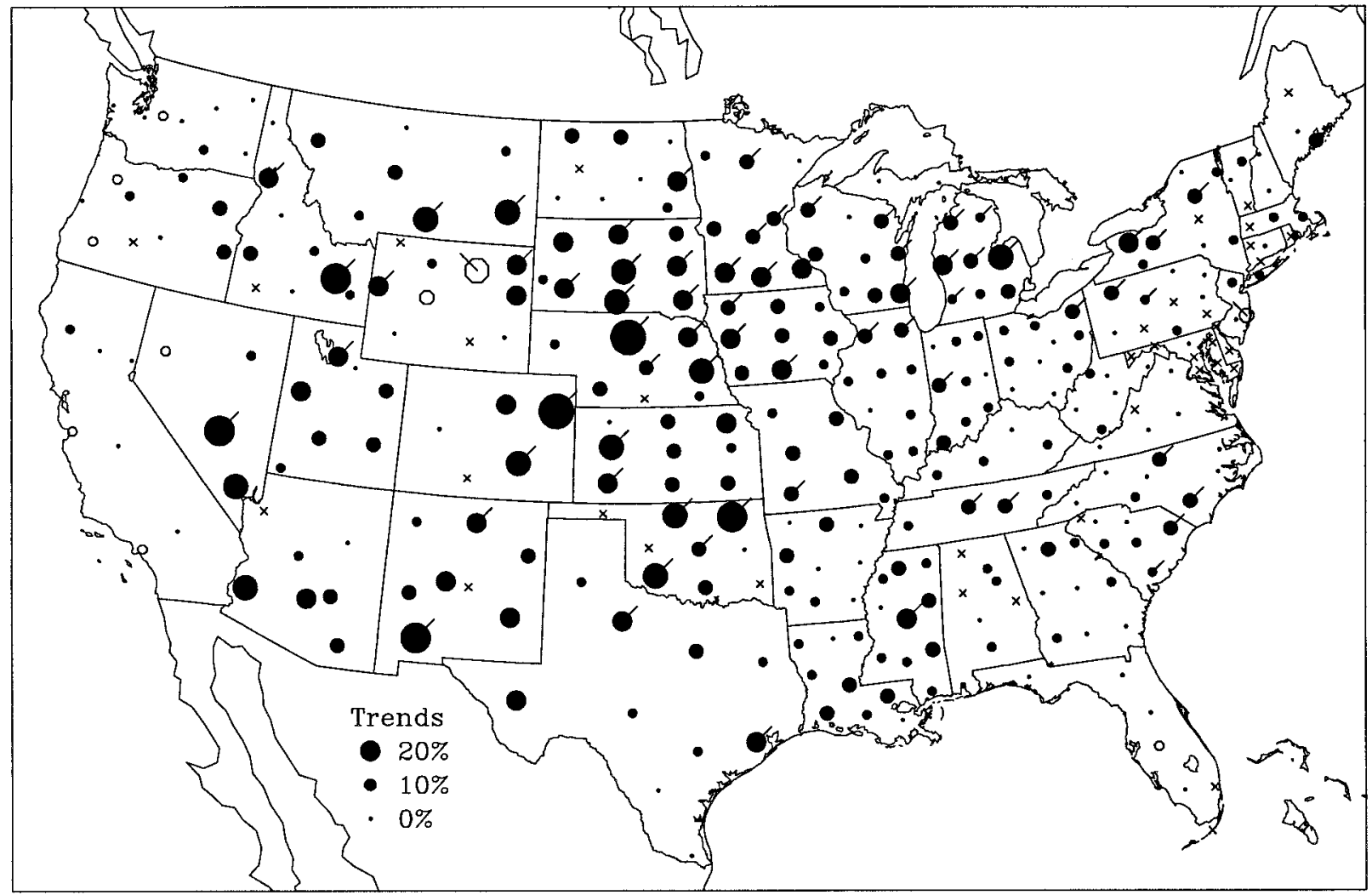

FIG. 9. United States climate division trends in total annual precipitation for 1931-96. Shaded circles indicate upward trends while open circles indicate downward trends. The magnitude of the trend is given in percent increase or decrease over the period 1931-96, relative to the long-term mean. As indicated by the key, the magnitude of the trend is linearly proportional to the radius of the circle. A tail attached to the upper right indicates positive trends with local significance at the 5\% level, two-tailed test; a tail attached to the upper left indicates locally significant negative trends. An " $X$ " indicates a climate division with no stations with complete records for the period 1931-96.

upper 10 percentile of daily precipitation events, which on average account for nearly $40 \%$ of total annual precipitation. Since the threshold for the 90th percentile is station specific, their analysis is similar to the method used here. However, the present analysis is restricted to the more extreme events. For example, precipitation from 1-yr recurrence, 7-day duration events accounts for about $15 \%$ of total precipitation, compared to $40 \%$ for the upper 10 percentile; of course, the contribution of events for the 5-yr recurrence and the 1- and 3-day duration will account for an even smaller percentage of total precipitation. Also, by examining multiday periods, the present analysis can identify trends in the frequency of extended periods where several excessive precipitation episodes occur in close temporal proximity. Such periods are often the cause of hydrologic flooding (Changnon and Kunkel 1995). In summary, the trends noted by Karl and Knight (1998) are clearly important to water resources in general and may have some implications for flood frequencies, although this is not entirely clear. By contrast, the present results, restricted to the more extreme events, are more narrowly applicable to flooding and to engineering design. No single measure of extreme precipitation will correlate highly with every type of flooding event and studies of different measures provide complimentary views of trends.

Although the methodology differs in these respects, the results are similar to the earlier findings. For the United States, Karl et al. (1995b) found a statistically significant upward trend in the percentage of total precipitation received in 1-day totals greater than $50.8 \mathrm{~mm}$ (2.0 in.) over the period 1911-92. Karl and Knight (1998) found that there has been an increase in the fractional contribution to total precipitation in the upper 10 percentile of daily precipitation events. Our linear trend analysis indicates that there has been an increase in the number of 7-day, 1-yr events over the period of 193196. The largest increases have occurred in a belt extending from the southwest United States across the Great Plains and middle Mississippi River valley into the Great Lakes basin. Some climate divisions have experienced increases of $50 \%-100 \%$. A composite index for the United States exhibits an average upward trend of $3 \%$ decade $^{-1}$, which is statistically significant at the $1 \%$ level. A national index for Canada does not exhibit a statistically significant upward trend for 1951-93. The areal coverage of U.S. climate divisions with local statistically significant upward trends exhibits field signif- 


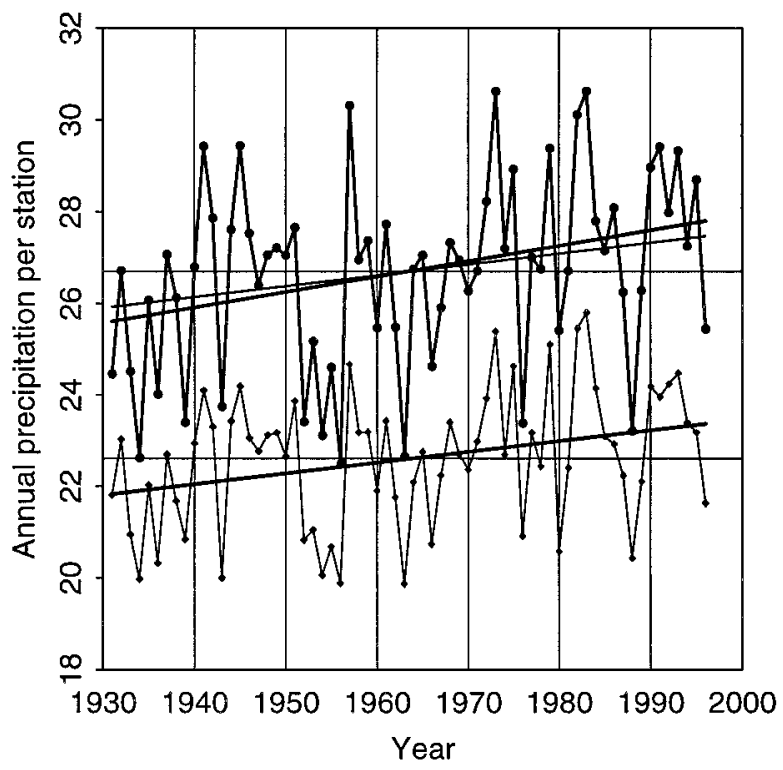

FIG. 10. Average total annual precipitation for the U.S. for 193196 (heavier line with dots). The heavy line shows the trend given by the Kendall slope estimator. The average annual precipitation without that involved in heavy precipitation events is shown by the lighter line with diamonds. For comparison, the trend for the latter is shown by a light line shifted up to the mean of the average total annual precipitation.

icance at the $5 \%$ level. The above results apply to events of 1-, 3-, and 7-day duration. However, the trend in 5-yr events, although upward, is not statistically significant.

The linear trend analysis is a simplication of the more complex temporal behavior of the time series. There is considerable low-frequency variability with extended periods of below-average number of events in the 1930s and 1950s and above average number of events in the early 1940s, early 1980s, and 1990s. The high-statistical significance of the trend results in part because the major drought periods of the 1930s and 1950s are in the early half of the time series. However, even when those periods are excluded by beginning the analysis in the 1960s, the magnitude of the upward trend remains high, although not as highly statistically significant. The frequency during the 1990s is on average higher than for any other period of comparable length during 1931-96. In an analysis of the percent area of the conterminous United States in severe moisture surplus for the period 1900-93, Karl et al. (1995a) found greater areas with moisture surplus for 1905-20, as well as well as the 1940s, 1970s, and 1980s. Our analysis of a 101-yr record of Midwestern stations shows that 7-day, 1-yr precipitation event frequencies around the turn of the twentieth century (1896-1906) were higher than for any other period of comparable length, except for 1986-96. Thus, for the Midwest, there is evidence of significant variability on the timescale of a century. Attribution of the cause of the recent upward trend should consider potential natural forcing factors that may make a sig-

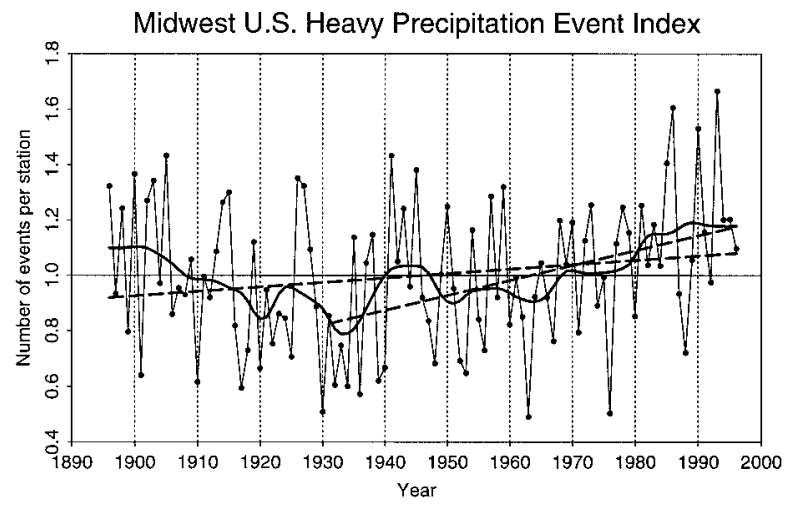

FIG. 11. Regionally averaged time series of the annual number of 7-day, 1-yr precipitation events for 1896-1996 for the midwestern states of Illinois, Indiana, Iowa, Kentucky, Michigan, Minnesota, Missouri, Ohio, and Wisconsin. The dashed lines are the trends given by the Kendall slope estimator for the periods 1896-1996 and 193196. The solid bold line is a smoothed average.

nificant contribution. There is no implication in these results that the upward trends will necessarily continue.

These results and the results of Karl and colleagues raise interesting questions, beyond the scope of this study, concerning the causes of these changes in frequency. Individual events, such as the 1993 floods, have been the subject of intense investigation of causes. Some of the factors that have been linked to that flood include the mature El Niño event (Bell and Janowiak 1995; Trenberth and Guillemot 1996), transient eddy activity in the North Pacific (Mo et al. 1995), and soil moisture anomalies (Beljaars et al. 1996). Ting and Wang (1997) have shown that the north Pacific sea surface temperature anomalies are related to summertime precipitation variability over the Unites States. These results raise interesting questions about whether the frequency of such causal factors has changed over time or whether other factors such as changes in atmospheric water vapor content have played an important role.

There are also important implications in these results for engineering design criteria. Although regional updates have been performed (Miller at al. 1973; Huff and Angel 1992), there has been no national analysis since that of Hershfield (1961). However, the large changes in frequency that have occurred since 1960 suggest that these results are in need of updating. Continued use of the results of Hershfield (1961) may result in serious underdesign of structures that deal with runoff.

Acknowledgments. We thank Jean Dennison for the professional and rapid preparation of this manuscript. This work was jointly supported by the National Oceanic and Atmospheric Administration Office of Global Programs and the U.S. Department of Energy in their Climate Change Detection and Attribution Project, under Grant NA66GP0445. The views expressed in this document are those of the authors and do not necessarily 
represent those of the National Oceanic and Atmospheric Administration.

\section{REFERENCES}

Beljaars, A. C. M, P. Viterbo, M. J. Miller, and A. K. Betts, 1996: The anomalous rainfall over the United States during July 1993: Sensitivity to land surface parameterization and soil moisture anomalies. Mon. Wea. Rev., 124, 362-383.

Bell, G. D., and J. E. Janowiak, 1995: Atmospheric circulations associated with the Midwest floods of 1993. Bull. Amer. Meteor. Soc., 76, 681-695.

Changnon, S. A., Ed., 1996: The Great Flood of 1993: Causes, Impacts, and Responses. Westview Press, $321 \mathrm{pp}$.

—, and K. E. Kunkel, 1995: Climate-related fluctuations in Midwestern flooding. J. Water Resour. Planning Manage., 121, 326334.

Goodison, B. E., and P. Y. T. Loule, 1986: Canadian methods for precipitation measurement and correction. Workshop on the Correction of Precipitation Measurements, Zurich, Switzerland, WMO, 141-145.

Groisman, P. Ya., and D. R. Easterling, 1994: Variability and trends of total precipitation and snowfall over the United States and Canada. J. Climate, 7, 184-205.

— cipitation data. Bull. Amer. Meteor. Soc., 75, 215-227.

Hershfield, D. M., 1961: Rainfall frequency atlas of the United States. U.S. Department of Commerce, Weather Bureau Technical Paper 40, 115 pp. [Available from National Technical Information Service, 5285 Port Royal Rd., Springfield, VA 22161.]

Hirsch, R. M., J. R. Slack, and R. A. Smith, 1982: Techniques of trend analysis for monthly water quality data. Water Resour. Res., 18, 107-121.

Huff, F. A., and J. R. Angel, 1992: Rainfall frequency atlas of the Midwest. Illinois State Water Survey Bulletin 71, 141 pp. [Available from Illinois State Water Survey, 2204 Griffith Dr., Champaign, IL 61820-7495.]

Hughes, P. Y., E. H. Mason, T. R. Karl, and W. A. Brower, 1992: United States historical climatology network daily temperature and precipitation data. Environmental Sciences Division Publication 3778, Carbon Dioxide Information and Analysis Center, Oak Ridge National Laboratory, Oak Ridge, TN, 55 pp. [Avail- able from National Technical Information Service, 5285 Port Royal Rd., Springfield, VA 22161.]

Karl, T. R., and R. W. Knight, 1998: Secular trends of precipitation amount, frequency, and intensity in the United States. Bull. Amer. Meteor. Soc., 79, 231-241.

_- P. Ya. Groisman, R. W. Knight, and R. R. Heim Jr., 1993: Recent variations of snow cover and snowfall in North America and their relation to precipitation and temperature variations. $J$. Climate, 6, 1327-1344.

— , R. W. Knight, D. R. Easterling, and R. G. Quayle, 1995a: Trends in U.S. climate during the twentieth century. Consequences, $\mathbf{1}$, $2-12$.

, and N. Plummer, 1995b: Trends in high-frequency climate variability in the twentieth century. Nature, 377, 217-220.

Kunkel, K. E., S. A. Changnon, and J. R. Angel, 1994: Climatic aspects of the 1993 upper Mississippi River basin flood. Bull. Amer. Meteor. Soc., 75, 811-822.

— climatic resources applications in the Midwestern United States. Bull. Amer. Meteor. Soc., 79, 1357-1366.

Leathers, D. J., D. R. Kluck, and S. Kroczyski, 1998: The severe flooding event of January 1996 across north-central Pennsylvania. Bull. Amer. Meteor. Soc., 79, 785-797.

Lettenmaier, D. P., E. F. Wood, and J. R. Wallis, 1994: Hydro-climatological trends in the continental United States, 1948-88. J. Climate, 7, 586-607.

Lins, H. F., and P. J. Michaels, 1994: Increasing U.S. streamflow linked to greenhouse forcing. Eos, Trans. Amer. Geophys. Union, 75, 281.

Livezey, R. E., and W. Y. Chen, 1983: Statistical field significance and its determination by Monte Carlo techniques. Mon. Wea. Rev., 111, 46-59.

Miller, J. F., R. H. Frederick, and R. J. Tracey, 1973: PrecipitationFrequency Atlas of the Western United States. NOAA Atlas 2, National Weather Service, 11 volumes. [Available from National Technical Information Service, 5285 Port Royal Rd., Springfield, VA 22161.]

Mo, K. C., J. Nogues-Paegle, and J. Paegle, 1995: Physical mechanisms of the 1993 summer floods. J. Atmos. Sci., 52, 879-895.

Ting, M., and H. Wang, 1997: Summertime U.S. precipitation variability and its relation to Pacific sea surface temperature. J. Climate, 10, 1853-1873.

Trenberth, K. E., and J. J. Guillemot, 1996: Physical processing involved in the 1988 drought and 1993 floods in North America. J. Climate, 9, 1288-1298. 